\title{
Ganzfeld electroretinographic findings in Parkinsonism: untreated patients and the effect of levodopa intravenous infusion.
}

\author{
M J JAFFE,* G BRUNO, $†$ G CAMPBELL, $\ddagger$ R A LAVINE, $§$ C N KARSON,* \\ D R WEINBERGER*
}

From the Neuropsychiatry branch, (WAW) Saint Elizabeth's Hospital, * National Institute of Mental Health, Washington, DC, Experimental therapeutics branch, $\dagger$ National Institute of Neurological and Communicative Disorders and Stroke. Bethesda, MD, Laboratory of statistical and mathematical methodology, DCRT, National Institute of Health, Bethesda, MD, Department of physiology, George Washington University,§ Washington, DC. Clinical branch, National Eye Institute, Bethesda, MD, USA

SUMMARY Two groups of patients with primary Parkinsonism were studied with the ganzfeld electroretinogram (ERG): (1) seven patients who had never received dopamimetic agents, and (2) six patients given an infusion of levodopa following a period of medication withdrawal. Patients in the first category had a subtle increase in the latency of their short-wavelength sensitive cone response recorded from the retina ipsilateral to their more symptomatic side. Most patients in the second category demonstrate an improvement in their ERG when the responses recorded following levodopa infusion were compared with baseline responses obtained during the period of medication withdrawal. These results suggest that one role of retinal dopamine may be maintenance of normal retinal responsiveness to flash stimuli.

Destruction of the nigrostriatal dopaminergic system is known to occur in patients with Parkinson's disease. ${ }^{1} \mathrm{~A}$ more generalised defect in dopaminergic neurotransmission in Parkinson's disease has been suggested. ${ }^{2}$ One possible clinical manifestation of a more global involvement is the prolonged latency of the visual evoked potential (VEP), the extent of which has been correlated with the clinical severity of the disease. $^{3}$ Two related findings suggest that the delayed VEP may be related to dopaminergic pathways in the retina. The first finding is the interocular differences in VEP latency. ${ }^{4}$ The second is that dopamine depleters and blockers increase latency of the VEP recorded over the visual cortex without altering the conduction time within the optic tract. ${ }^{5}$

Compared with the VEP, a more localised evaluation of neuronal activity within the retina can be obtained with the electroretinogram.(ERG). ${ }^{6}$ Studies with rabbits show that $\mathrm{N}$-methyl-phenyl-

Address for reprint requests: Myles Jay Jaffe, WAW, NIMH, 2700 Martin Luther King Ave., Washington, DC 20032, USA.

Received 8 July 1986 and in revised form 4 December 1986. Accepted 5 December 1986 tetrahydropyridine (MPTP), a neurotoxin that causes a Parkinson-like disease in primates and humans ${ }^{7}$ also decreases the ERG scotopic b-wave amplitude and increases its latency. ${ }^{8}$ Initial ERG studies in patients with Parkinsonism have shown that high doses of levodopa attenuate the b-wave when there are associated signs of levodopa toxicity. ${ }^{910}$ In our study, we evaluated neurophysiological changes in the retina of patients with early Parkinsonism and, in addition, examined the effects of levodopa infusion on patients withdrawn from oral dopamimetic agents.

\section{Methods}

Subject selection

All patients in these studies were diagnosed with primary Parkinsonism and gave informed consent.

Patients not previously treated with dopaminergic agonists Six males and one female with a mean age of 55.7 years $( \pm S . D .7 \cdot 0)$ gave informed consent to participate. None had been treated with dopaminergic agonists. Each had some lateralisation of Parkinsonism symptoms (table 1). The severity of the disease was rated according to the stages of Hoehn and Yahr. ${ }^{11}$ Two patients were classified with stage I disease and five with stage II disease (table 1). The mean duration of the disease was 3.6 years $( \pm$ S.D. $2 \cdot 1)$. 
Table 1 Demographics and staging of patients not treated with dopamimetics.

\begin{tabular}{|c|c|c|c|c|c|c|c|}
\hline \multirow[b]{2}{*}{ Patient } & \multirow[b]{2}{*}{ Age (yr) } & \multirow[b]{2}{*}{ Sex } & \multirow[b]{2}{*}{ Stage } & \multirow{2}{*}{$\begin{array}{l}\text { Disease } \\
\text { Duration }\end{array}$} & \multicolumn{3}{|c|}{ Clinical Ratings (Right/Left) } \\
\hline & & & & & Bradykinesia* & Rigidity* & Tremor* \\
\hline $\begin{array}{l}1 \\
2 \\
3 \\
4 \\
5 \\
6 \\
7\end{array}$ & $\begin{array}{l}65 \\
62 \\
58 \\
54 \\
45 \\
57 \\
49\end{array}$ & $\begin{array}{l}\mathbf{M} \\
\mathbf{M} \\
\mathbf{M} \\
\mathbf{M} \\
\mathbf{M} \\
\mathbf{F} \\
\mathbf{M}\end{array}$ & $\begin{array}{l}\text { II } \\
\text { I } \\
\text { I } \\
\text { II } \\
\text { II } \\
\text { II } \\
\text { II }\end{array}$ & $\begin{array}{l}1 \mathrm{y} \\
2 \mathrm{y} \\
2 \mathrm{y} \\
3 \mathrm{y} \\
5 \mathrm{y} \\
5 \mathrm{y} \\
7 \mathrm{y}\end{array}$ & $\begin{array}{r}+10 \\
0 / 0 \\
0 / 0 \\
+1+ \\
++10 \\
+10 \\
0 / 0\end{array}$ & $\begin{array}{r}0 / 0 \\
0 / 0 \\
0 / 0 \\
0 / 0 \\
+++1+ \\
0 / 0 \\
0 /+\end{array}$ & $\begin{array}{l}+10 \\
0 / 1 \\
+10 \\
0 /+ \\
0 / 0 \\
+10 \\
0 /+\end{array}$ \\
\hline
\end{tabular}

Parkinsonian symptoms were in each case more pronounced on one side. ${ }^{*}$ evaluated during a clinical neurological examination using a $0-4^{+}$ scale.

Ophthalmic criteria for eligibility included a best corrected visual acuity of $20 / 20$ or better in each eye and normal confrontation visual fields, intraocular pressure, slit lamp examination and fundus examination OU. Both eyes of each patient underwent a ganzfeld ERG. ERG results from the eye ipsilateral to the more affected side were compared with those from the contralateral side. The subjects were always tested in the late afternoon by the same examiner. Patients were requested to abstain from caffeinated beverages and from tobacco for 18 hours prior to testing.

Patients receiving levodopa infusion following a period of withdrawal from dopamimetics Five males and one female with a mean age of 60.3 years $( \pm$ S.D. 5.7) participated. Of the six patients tested, two had stage II disease and four had stage III disease (table 2). The mean duration of their disease was 12.0 years $( \pm$ S.D. $5 \cdot 8)$. Four patients had been receiving levodopa in combination with carbidopa (Sinemet). Their mean daily dose prior to withdrawal was $1050 \mathrm{mg} / \mathrm{kg}$ ( \pm S.D. 227). One patient had been on lisuride and one patient had been treated with trihexyphenidyl. Patients were withdrawn from their medication for a mean duration of 51.0 hours (S.D. $\pm 21 \cdot 2$ ) (range 14 to 72 hours). Baseline ERGs were recorded in the evening prior to the administration of levodopa. Intravenous infusion of levodopa began the following morning at approximately 9 a.m.

Following the onset of the infusion, each patient was given a minimum of 2 hours to stabilise on the first drug dose (drug dosage was pre-determined individually for each patient, table 2). Carbidopa was administered by mouth at a dose of $50 \mathrm{mg} / 3$ hours. Patients were then taken by wheel chair to the ERG testing room. Two patients showed dramatic changes in their ERG following the first dose (one improved and the other deteriorated). These two patients had their dose doubled and were again stabilised for 2 hours prior to the recording of a final ERG.

\section{Electroretinography}

Cycloplegia and mydriasis were obtained with $1 \%$ tropicamide and $2.5 \%$ neosynephrine in the eyes to be tested. Dark adaptation was conducted in the ERG testing room for a minimum of 30 minutes. A Burian-Allen contact lens electrode $^{12}$ was then mounted using buffered methylcellulose for cushioning. A ground electrode was taped to the forehead. The subject sat facing a ganzfeld stimulation system ${ }^{13}$ which was constructed from a world globe; the patient's entire face fits inside the globe. This ganzfeld provided homogeneous test flashes and background illumination. Flashes of $10 \mu$ s duration were generated with a modified Grass PS22 photostimulator, and calibrated using a Pritchard 1980B photometer. Flashes were delivered serially beginning with the lowest intensity. With this paradigm, we obtained our log I response profiles. The recording system consisted of a Grass P15 amplifier and a Nicolet signal averager. While the patient was dark-adapted, both the rod and dark-adapted cone responses were recorded. To isolate the rod component of the ERG, a Wratten 47B filter (blue) was interposed between the Grass flash tube and light port into the ganzfeld. ${ }^{14}$ The dark-adapted red-green cone potentials were isolated using a Wratten 21 filter (red).

To isolate the blue-cone response, a blue flash, generated using the same 47B filter, was super-imposed on a $6.1 \mathrm{fL}$ yellow background created with a Wratten 26 filter. ${ }^{15}$ Using this stimulus configuration, the longer-wavelength sensitive cones and rods were light adapted while the blue-sensitive cones remained dark adapted. Light adaptation with this

Table 2 Patient demographics and clinical characteristics of individuals tested in the levodopa infusion study.

\begin{tabular}{|c|c|c|c|c|c|c|c|c|c|c|}
\hline Patient & $\begin{array}{l}\text { Age } \\
(y r)\end{array}$ & Sex & Stage & $\begin{array}{l}\text { Disease } \\
\text { Duration }\end{array}$ & $\begin{array}{l}\text { Lateralisation } \\
\text { of symptoms }\end{array}$ & $\begin{array}{l}\text { History } \\
\text { of levodopa }\end{array}$ & $\begin{array}{l}\text { Dose prior } \\
\text { to holiday }\end{array}$ & $\begin{array}{l}\text { Interval } \\
\text { off-meds }\end{array}$ & $\begin{array}{l}\text { Dose } \\
\text { levodopa }\end{array}$ & $\begin{array}{l}\text { Clinical } \\
\text { Improvement }\end{array}$ \\
\hline 1 & 58 & $\mathbf{M}$ & II & $7 y$ & Right & $5 y$ & \multirow{2}{*}{$\begin{array}{l}1000 \mathrm{mg} / \text { day } \\
\text { Sinemet } \\
\text { No levodopa }\end{array}$} & $49 \mathrm{~h}$ & \multirow{2}{*}{$\begin{array}{l}0.5 \& 1.0 \\
\mathrm{mg} / \mathrm{ml} / \mathrm{min} \\
2.5\end{array}$} & Yes \\
\hline 2 & 55 & $\mathbf{M}$ & II & $9 y$ & Right & - & & $51 \mathrm{~h}$ & & Yes \\
\hline 3 & 61 & $\mathbf{M}$ & III & $9 y$ & Bilateral & $7 y$ & \multirow{4}{*}{$\begin{array}{l}1200 \mathrm{mg} / \text { day } \\
\text { Sinemet } \\
1250 \mathrm{mg} / \text { day } \\
\text { Sinemet } \\
2.8 \mathrm{mg} / \text { day } \\
\text { Lisuride } \\
750 \mathrm{mg} / \text { day } \\
\text { Sinemet }\end{array}$} & $14 \mathrm{~h}$ & 0.76 & \multirow{2}{*}{$\begin{array}{l}\text { Initial } \uparrow \text { then } \\
\text { dyskin } \\
\text { No }\end{array}$} \\
\hline 4 & 70 & $\mathbf{M}$ & III & $9 y$ & Bilateral & $7 y$ & & $72 \mathrm{~h}$ & 0.5 & \\
\hline 5 & 55 & $\mathrm{~F}$ & III & $16 y$ & Left & $14 y$ & & $72 \mathrm{~h}$ & 0.5 & No \\
\hline 6 & 63 & $\mathbf{M}$ & III & $22 y$ & Left & $19 y$ & & $48 \mathrm{~h}$ & $1.0 \& 2.0$ & Yes \\
\hline
\end{tabular}


yellow background was continued for a minimum of 2 minutes before the blue flashes were started.

ERG oscillatory potentials (OPs) were elicited under conditions of both dark- and light-adaptation; only the highest intensity flash was used. Under conditions of darkadaptation both red and white flashes were used; under conditions of light-adaptation only white flashes were used. To record the OPs, the analogue ERG signal was filtered between 70 and $250 \mathrm{~Hz}$; the interstimulus delay was $30 \mathrm{sec}$ onds in accordance with the procedure of Algevere and Westbeck. ${ }^{16}$ For all waveforms except for the OPs, four responses were averaged in cooperative patients. For the OPs, the response to the first flash was discarded and the next two responses were averaged when averaging was possible. Under the conditions described, the OPs show virtually no variability between responses.

Light-adapted cone responses were obtained using white flashes superimposed on a white background (11.5 fL). Subjects were exposed to this background light for a minimum of 1 minute before the white flashes were begun.

\section{Statistical analysis}

An analysis of variance for repeated measures and two "within" factors was used to evaluate both the effects of lateralised disease and to examine the effects of the levodopa infusion. The two factors for the first study were the disease laterality and the stimulus intensity. In the second study, the two factors were the drug effect and the stimulus intensity. The data were analysed using the General Linear Model of the SAS software package (ed. 4, SAS Institute; Cary, N.C.).

\section{Results}

\section{Untreated patients}

The latency of the blue cone response was prolonged when the ERG obtained ipsilateral to the impaired side was compared to that recorded from the contralateral eye. The latency of the ipsilateral ERG was prolonged by a mean of 3\% across all intensities; this trend was more manifest at higher intensities. This asymmetry, although significant at the $\mathrm{p}<0.01$ level, loses statistical significance when the Bonferoni correction (BFC) is made. The mean +1S.D. for each intensity is provided in table 3.

\section{Patients treated with levodopa infusion}

Under conditions of dark-adaptation, the rod b-wave increased in amplitude by a mean of $12 \%$ across all intensities following infusion of levodopa, $(p<0.002$

Table 3 Latency data for the blue-sensitive cone response. $V$ alues are expressed as the mean $\pm 1 S$.D. in units of milliseconds.

\begin{tabular}{lll}
\hline Intensity & $\begin{array}{l}\text { ERG latency contralateral to } \\
\text { the most affected side }\end{array}$ & $\begin{array}{l}\text { ERG latency ipsilateral to } \\
\text { the most affected side }\end{array}$ \\
\hline $\mathrm{I}-2$ & $56 \pm 3 \mathrm{~ms}$ & $57 \pm 4 \mathrm{~ms}$ \\
$\mathrm{I}-4$ & $52 \pm 2 \mathrm{~ms}$ & $53 \pm 3 \mathrm{~ms}$ \\
$\mathrm{I}-8$ & $48 \pm 2 \mathrm{~ms}$ & $49 \pm 3 \mathrm{~ms}$ \\
$\mathrm{I}-16$ & $42 \pm 3 \mathrm{~ms}$ & $44 \pm 3 \mathrm{~ms}$ \\
\hline
\end{tabular}

following the BFC) (fig 1A). Under conditions of light-adaptation, the a-wave amplitude increased by a mean of $12 \%$ in amplitude $(\mathrm{p}<0.02$ following the BFC) and the b-wave increased by a mean of $24 \%$ in amplitude, ( $p<0.002$ following the BFC) (fig 1B and C). Although there is a significant trend for levodopa to enhance the amplitude of several parameters of the ERG, inspection of figure 1 shows that at some intensities no effect of levodopa could be demonstrated. Amplitude enhancement under conditions of light adaptation occurred in association with a mean $2 \%$ decrease in the latency of the light-adapted $b$-wave (p $<0.002$ following the BFC); both amplitude enhancement and a faster latency to peak reflect a relative improvement in the ERG.

In the light of general ERG improvement, it is interesting that two patients displayed divergent patterns of drug response. Patient 1 was treated initially with $0.5 \mathrm{mg} / \mathrm{ml} / \mathrm{min}$ infusion. This resulted in a general increase of amplitude and decrease of latency with respect to baseline values (fig 2). Prior to record-
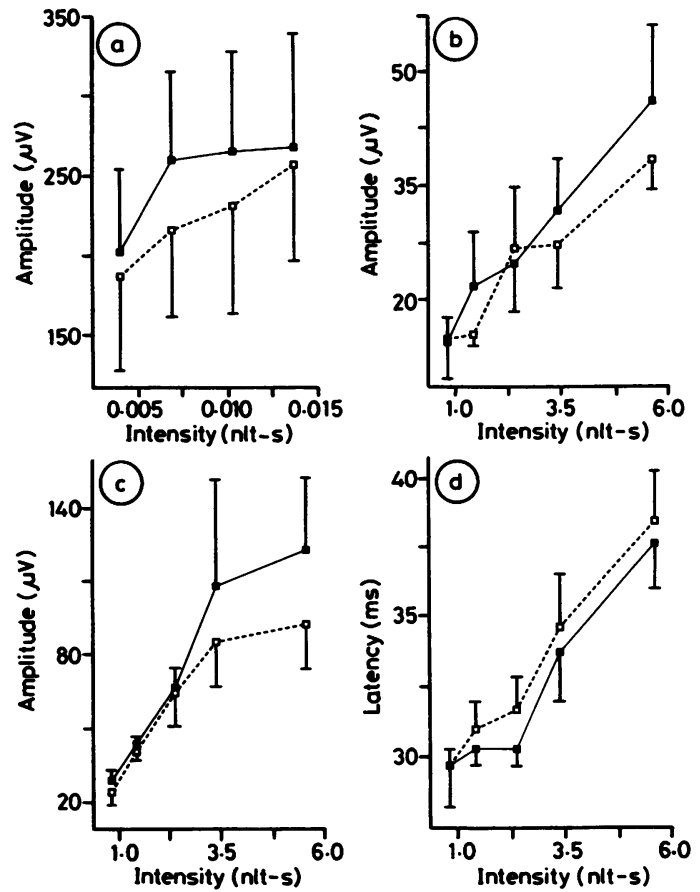

Fin 1 A: levodopa enhances the amplitude of the rod $b$-wave and both the $a$ - and $b$-waves of the light-adapted cones ( $B$ and $C$ respectively). Baseline is represented by the dotted line and the drug effect by the solid line. The mean increase (\% $\%$ ) across all intensities for the rod b-wave is $12 \%$, for the light-adapted cone a-wave $15 \%$, and for the light-adapted cone b-wave $24 \%$. D: levodopa concurrently decreases the latency of the ERG light-adapted cone b-wave by $2 \%$ across all intensities. 


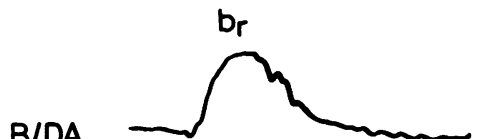

B/DA
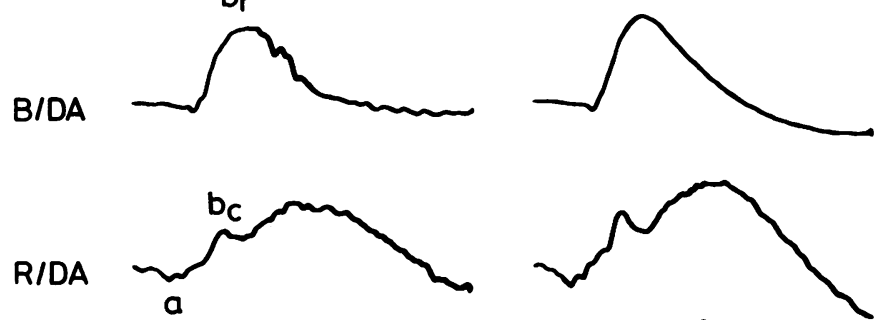

R/DA

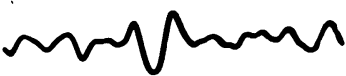

WIDA

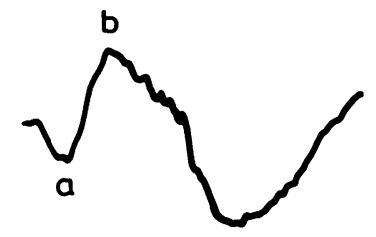

W/DA

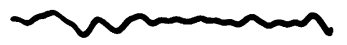

B/YA

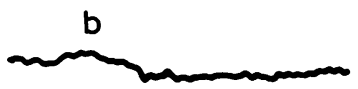

WILA

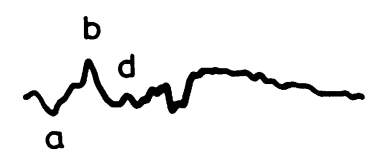

${ }_{W I L A} \sim N M$
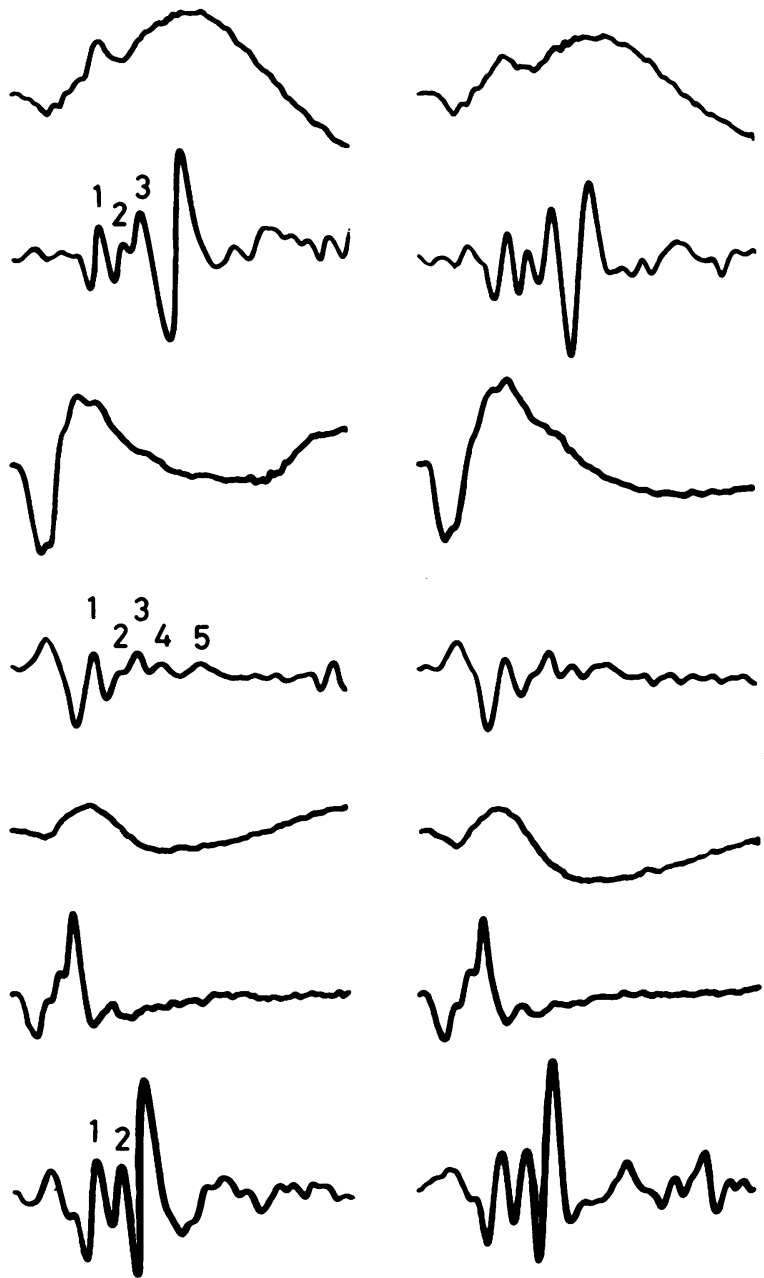

Fig 2 Enhancement of the ERG following levodopa infusion. These are the actual waveforms of patient 1. Column 1 refers to the baseline response; column 2 to the waveforms following $0.5 \mathrm{mg} / \mathrm{ml} / \mathrm{min}$; column 3 to the waveforms following $1.00 \mathrm{mg} / \mathrm{ml} / \mathrm{min}$. The gain and time base are constant in columns 1,2 and 3 . $B / D A$ refers to the blue flash under dark-adapted conditions which will elicit the rod response; $b(r)$ depicts the peak of the rod b-wave. R/DA refers to the red flash under dark-adapted conditions; this stimulus elicits the $R-G$ cone response. The peak of the cone a-wave is denoted by " $a$ " and the peak of the cone $b$-wave is denoted by $b(c)$. When this latter response is filtered between 70 and $250 \mathrm{~Hz}$, only the fast components of the waveform remain $R / D A(f)$. These are the dark-adapted oscillatory potentials. They are not recognisable in the baseline responses but become detectable upon administration of i.v. levodopa $(O P s 1,2,3) . W / D A$ stands for a white flash under conditions of dark-adaptation. This evokes a mixed rod and cone $a$ - and $b$-wave. Neither the rod nor the cone contribution can be separated from the mixed-response. When this response is filtered, as above, five oscillatory potentials can be discerned $(W / D A(f))$. Here again, these are only vaguely identifiable in the baseline recording but are evident following levodopa infusion. B/YA represents the "blue-cone" response and is recorded from the retina when a blue flash is super-imposed on a yellow background. Although present in the baseline condition, the blue cone $b$-wave $(b)$ increases following levodopa. W/LA indicates a white flash under conditions of lightadaptation. In addition to the cone $a$-wave and b-wave, the light adapted response is characterised by the presence of a d-wave. ${ }^{6}$ The amplitude of all three waves increases following levodopa. Similarly, the amplitude of the light-adapted $O P S(W / L A(f))$ improves with levodopa. 
1

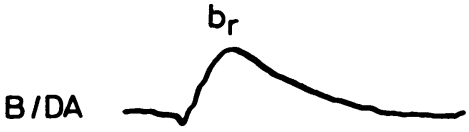

B/DA

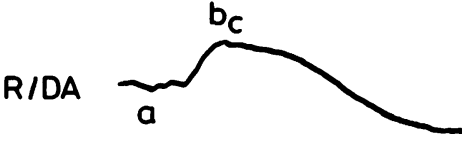

R/DAf

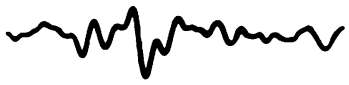

WIDA $\int_{a}^{b}$

WIDAf
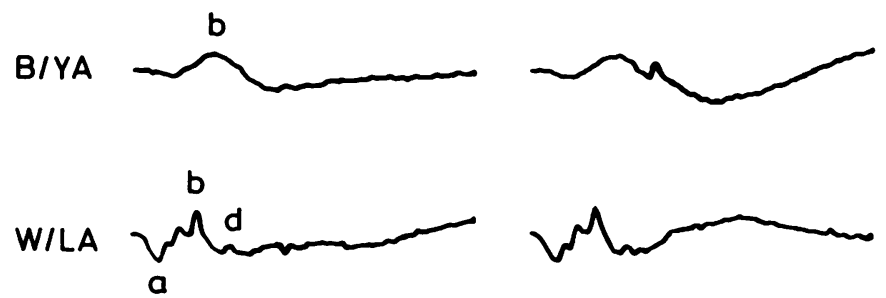

WILAf NMWrar
2
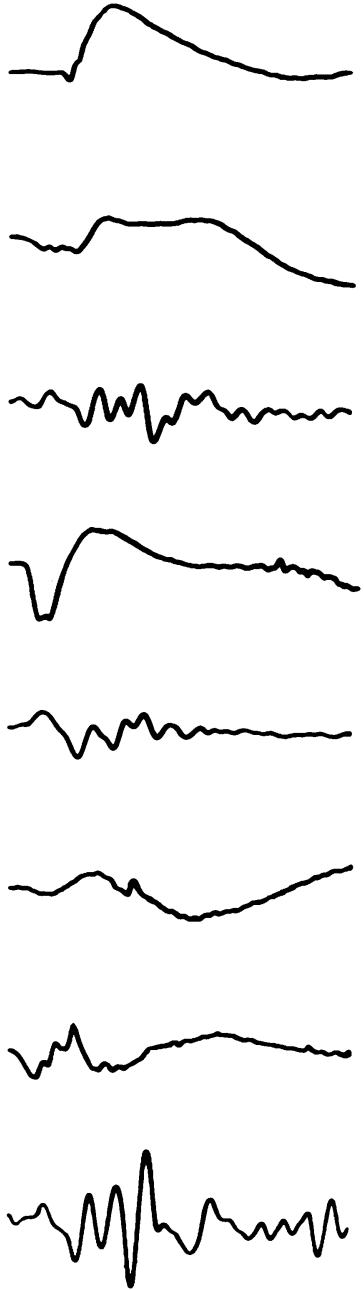
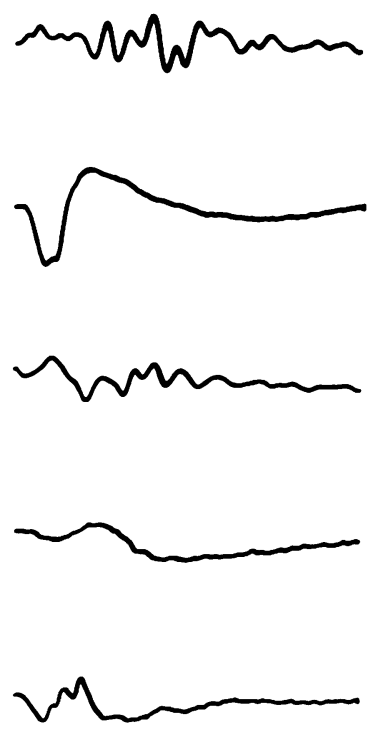

3
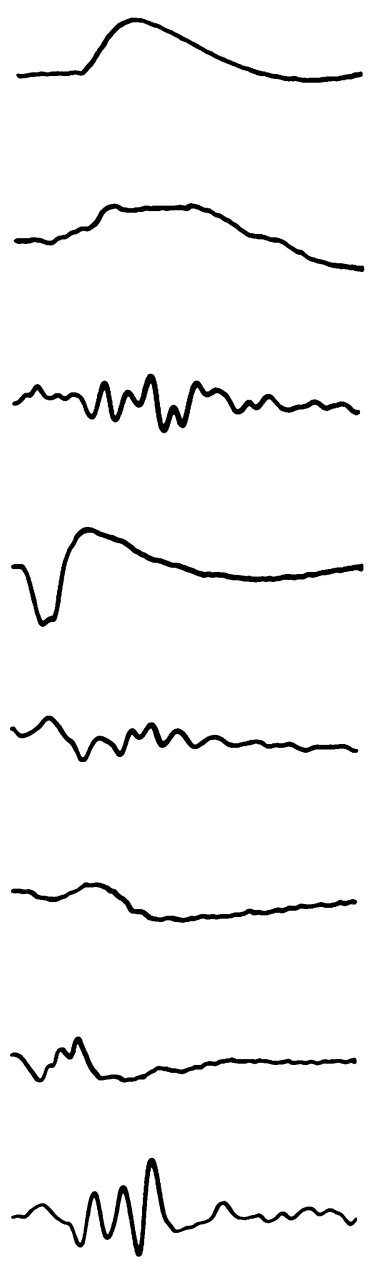

Fig 3 Deterioration of the ERG following levodopa infusion. These are the actual waveforms of patient 6. The format for this figure is identical to fig 2 as are the abbreviations. In this patient, column 1 represents baseline; column 2 represents $1 \mathrm{mg} / \mathrm{ml} / \mathrm{min}$; column 3 represents $2 \mathrm{mg} / \mathrm{ml} / \mathrm{min}$.

ing the final ERG, the dose was doubled to $1.0 \mathrm{mg} / \mathrm{ml} / \mathrm{min}$. This dose accentuated the positive trends for the rods, but had little additional effect on the blue-cone response, light-adapted cones or the oscillatory potentials. The long-wavelength sensitive cone (RG) b-wave was attenuated at this dose.

Patient 6 was treated with an initial dose of $1.0 \mathrm{mg} / \mathrm{ml} / \mathrm{min}$ and a final dose of $2.0 \mathrm{mg} / \mathrm{ml} / \mathrm{min}$. In this case, levodopa infusion resulted in a generalised dose-dependent decrement in both the dark- and light-adapted ERG. This was manifested in a general amplitude decrease and latency increase (fig 3 ).

\section{Discussion}

Intravenous infusion of levodopa can affect the ERG in patients with Parkinson's disease, indicating that the human retina is sensitive to changes in the systemic levels of levodopa and that this drug or its metabolite cross the blood-retinal barrier. In addition, a 
subtle ERG deficit of the blue-cone response may be manifest in the early stages of the disease despite the normal appearance of the fundus and 20/20 or better Snellen visual acuity.

The enhancement of the a-wave by levodopa under conditions of light adaptation indicates an action of levodopa or of dopamine at the level of the photoreceptors ${ }^{617}$ and is consistent with the recent evidence of dopamine receptors on the outer segments of photoreceptors. ${ }^{1819}$ The general findings of the levodopa infusion study are consistent with the ERG recovery pattern seen in patient 1 (fig 3 ). This pattern of recovery resembles that observed in rabbits ${ }^{20}$ and in cats ${ }^{21}$ in which reserpine attenuated the ERG and subsequent administration of levodopa (but not of norepinephrine) resulted in a return of the waveform toward normal. Corroborative results have been obtained in rats administered with dopaminergic blockers followed by dopaminergic agonists. ${ }^{5}$

In a clinically-related study, Parkinsonian patients received a VER before and after treatment with levodopa. $^{22}$ The latency decreased in nine out of 14 patients, changed only slightly in four and increased in one patient. In two patients, latency shortened in one eye and became longer in the other. Thus, while most subjects showed enhanced VER responses, three of 14 patients provided evidence for a decrement in visual responsiveness following levodopa administration. These data approximate our findings in which one of 6 patients showed a generalised ERG decrement (Patient 6; table 2); these data may be consistent with the neurotoxic effect of levodopa demonstrated by others. ${ }^{910}$ Our collective data suggest that the retina is at least one element in the visual system where modulation of dopamine may regulate the responsiveness to light flashes.

This study was conducted as part of the research requirements for Doctor of Philosophy degree offered by the Department of Physiology, George Washington University. We thank John C Coen for his technical assistance in this study.

\section{References}

1 Hornykiewicz O. Dopamine (3-hydroxytyramine) and brain function. Pharmacol. Rev. 1966;18:925-64.

2 Barbeau A, Campanella G, Butterworth R, Yamada K. Uptake and efflux of ${ }^{14} \mathrm{C}$-dopamine in platelets: Evidence for a generalized defect in Parkinson's disease. Neurology 1975;25:1-9.

3 Bodis-Wollner, Yahr M, Mylin L. VEP latency changes due to neurotransmitter deficiency in humans. Trans. Am. Neurolg. Assoc. 1980;105:1-3.

4 Bodis-Wollneor I, Yahr M. Measurements of visual evoked potentials in Parkinson's disease. Brain 1978;101:661-671.

5 Dyer RS, Howell WE, MacPhail RC. Dopamine depletion slows retinal transmission. Exp. Neurol. 1981;71:326-40.

6 Brown KT. The electroretinogram: its components and their origins. Vision Res. 1968;8:633-77.

7 Burns RS, Chiueh CC, Markey SP, Ebert MH, Jacobowitz DM, Kopin IJ. A primate model of Parkinsonism: selective destruction of dopaminergic neurons in the pars compacta of the substantia nigra by N-methyl 1-4-phenyl 1, 2, 3, 6 tetrahydropyridine. Proc. Natl. Acad. Sci. USA. 1983;80:4546-50.

8 Wong C, Ishibashi T, Tucker G, Hamasaki D. Responses of the pigmented rabbit retina to NMPTP, a chemical inducer of Parkinsonism. Exp. Eye Res. 1985;40:509-519.

9 Cavallacci G, Perossini M. Interet clinique du test electroretinographique dans la maladie de Parkinson. $J$. Fr. Ophtalmol. 1979;2:705-709.

10 Iudice A, Virgili P, Muratorio A. The electroretinogram in Parkinson's disease. Res. Commun. Psychol., Psychiat., Behav. 1980;5:283-8.

11 Hoehn MM, Yahr MD. Parkinsonism: onset, progression, and mortality. Neurology 1967;17: 427-42.

12 Burian HM, Allen LA. A speculum contact lens electrode for electroretinography. Electroencephalogr. Clin. Neurophysiol. 1954;6:509-11.

13 Gunkel RD, Bergsma DR, Gouras P. A ganzfeld stimulator for electroretinography. Arch. Ophthalmol. 1976;94:669-670.

14 Berson EL, Gouras P, Gunkel RD. Rod responses in retinitis pigmentosa, dominantly inherited. Arch. Ophthalmol. 1968;80:58-70.

15 Van Norren D, Padmos P. Human and macque blue cones studied with electroretinography. Vision Res. 1973;13:1241-54.

16 Algevere P, Westbeck S. Human ERG in response to double flashes of light during the course of dark adaptation: a fourier analysis of the oscillatory potentials. Vision Res. 1972;12:195-214.

17 Heynen H, Van Norren D. Origin of the electroretinogram in the intact macque eye. Vision Res. 1985;25:697-707.

18 Brann MR, Jelsema CL. Dopamine receptors on photoreceptor membranes couple to a GTP-binding protein which is sensitive to both pertussis and cholera toxin. Biochem. Biophys. Res. Commun. 1985;133:222-27.

19 Dearry A, Burnside B. Dopamine inhibits Forskolinand 3-isobutyl-1-methylxanthine-induced darkadaptive retinomotor movements in isolated teleost retinas. J. Neurochem. 1985;44:1753-63.

20 Hempel FG. Modification of the rabbit electroretinogram by reserpine. Ophthalamol. Res. 1973;4:65-75.

21 Guiterrez OC, Spiguel RD. Oscillatory potentials of the cat retina: effects of adrenergic drugs. Life Sci. 1973;13:991-9.

22 Bodis-Wollner I, Yahr M, Mylin L, Thornton J. Dopaminergic deficiency and delayed visual evoked potentials in humans. Ann. Neurol. 1982;11:478-83. 